\title{
Mitral Valve Prolapse: - The Facts
}

\section{Lt Col J H Johnston, FRCP FRCP(Glasg), RAMC \\ Consultant Physician}

Duchess of Kent's Military Hospital, Catterick Garrison, North Yorkshire DL9 4DF

SUMMARY: Mitral Valve Prolapse does not cause chest pain or other symptoms and is extremely unlikely to give rise to complications. In practice it is difficult to differentiate a 'prolapsing' valve from one that is 'normal' no matter what methods are used. Since diagnosing 'heart disease' is itself a well known cause of ill health, the most stringent criteria must be adopted before the mitral valve is labelled as being abnormal. The need for the diagnosis at all is, in most cases, doubtful.

'Le coeur a ses raisons que la raison ne connaît point.'

Pascal

\section{Introduction}

Mitral Valve Prolapse (MVP) is a condition which is claimed to have a long military history ${ }^{1}$. Although some thousands of papers on MVP have been published over the past 25 years it has continued to present some ambiguous features and its clinical relevance has not always been clear. It is hoped that this account of the established facts may help to dispel some of the mystique surrounding the disorder and perhaps even assist in the management of some patients. Mitral Valve Prolapse simply means that part of the mitral valve slips from the ventricle into the atrium during systole.

\section{Detection?}

Prolapse can be shown or suspected in different ways:-

Pathologically At autopsy, or during open heart surgery, obviously abnormal valves, termed 'floppy' or 'myxomatous'2 can be found as part of a general connective tissue defect, and also in otherwise normal people $^{3}$. The floppy valve certainly prolapses ${ }^{3}$ and is now the commonest cause of severe mitral incompetence requiring surgery ${ }^{4}$, but is of doubtful relevance otherwise.

On Auscultation Mid- or late- systolic 'clicks' can occur without other signs and are thought often to arise from the mitral valve apparatus 5 . Single or multiple clicks may usher in a late-systolic cardiac murmur or occur in the middle of a pan-systolic murmur. The murmurs are due to mitral regurgitation ${ }^{5,6}$ (though if confined to late systole this is trivial ${ }^{7}$ ). The combination of click and a trivial regurgitant murmur is generally agreed usually to indicate prolapse of a portion of the mitral valve. (Other cardiac abnormalities can cause similar murmurs but not often with a $\operatorname{click}^{8}$ ). There are widely differing estimates of how common these findings are $^{9}$, but clinical experience would support those which give a prevalence of about $1 \%$ in the general population. In young, thin, narrow chested people, and particularly in women, the prevalence is higher but diminishes with age and increasing build ${ }^{10}$, strongly suggesting that it can be a transitory (and presumably normal) phenomenon. Unfortunately MVP may be wrongly diagnosed by the misinterpretation of normal findings (eg a split first heart sound may be mistaken for a click and a mid-systolic murmur may be thought to be late-systolic). It is important also to know that indistinct systolic sounds are not clicks and that late-systolic murmurs must, bæ definition ${ }^{7}$, extend into the second heart sound. A late systolic murmur without a click is sometimes due to papillary muscle dysfunction which can have differer causes $^{7}$. A pan-systolic murmur indicates that significate 'Mitral Incompetence', rather than MVP is the appropriate diagnostic label. A click on its own is of n\& significance.

Ultrasonographically $\mathrm{M}$ - Mode echocardiography류 introduced in the $1960 \mathrm{~s}$, allowed easy, non-invasive, visualisation of the interior of the heart. It seemed that a substantial proportion of people had abnormal movement of the mitral valve into the left atrium during systole $^{11}$. It has since been demonstrated however that the M - Mode echocardiogram is subject to much observer error particularly in accurate identification of the position of the mitral valve closure line ${ }^{12}$ and also that the diagnostic criteria used were insufficiently precise $^{13}$. The later introduction of two-dimensional (2 D) echocardiography gave rise to hopes that MVP could be more accurately identified ${ }^{12}$, but this has proved not to be the case, probably because the mitral annulus is 'saddle-shaped' rather than, as had always been assumed, planar ${ }^{14}$. Doppler cardiography has also not yet proved useful and the examination of choice at present seems to be ' $2 \mathrm{D}$ - targeted' $\mathrm{M}$ - Mode echocardiography ${ }^{13}$. This will clearly identify obviously floppy, incompetent valves but there is no clear dividing line between normal and mild prolapse. At least $3 \mathrm{~mm}$ mid- or late-systolic buckling of the mitral valve should o probably be demonstrated before echocardiographic $N$ MVP is diagnosed; pan-systolic bowing should not now be accepted as indicating prolapse ${ }^{13}$. 
Angiographically MVP was first identified as such in left heart catheter studies ${ }^{15}$ but it is obvious that invasive procedures can only be used in exceptional circumstances. Even so, the accuracy of this method is uncertain since different observers do not always agree closely on whether prolapse is angiographically present or $\operatorname{not}^{16}$.

By Combinations of Methods A diagnosis is more convincing if it can be cross-checked but the agreement between the different investigative methods has usually been poor when comparisons have been made ${ }^{13}$. Pathological series ${ }^{2,3}$ have included only subjects who have died or who have had severe mitral incompetence

- requiring valve replacement and have not been relevant to those with MVP suspected by the other methods, who have usually had little clinical abnormality. Many people with auscultatory signs have no echocardiographic abnormalities and vice-versa ${ }^{11}$; those with angiographic prolapse often have not had echocardiographic or auscultatory signs ${ }^{13}$. In fact it has not been clearly established that it is the same disorder that is being detected by the different investigations! Simply listening to the heart has certainly not been shown to be inferior to more sophisticated and expensive techniques.

\section{Does MVP Matter?}

The clinical basis for the disorder, which is what matters for most doctors (and patients), has been the reported associated symptoms: different combinations of chest pain, breathlessness, palpitations, fainting, anxiety, and ECG changes ${ }^{17}$ as well as worry about whether there might be serious complications such as cardiac arrhythmias ${ }^{17}$, sudden death ${ }^{5,17}$, bacterial endocarditis $^{18}$, stroke $^{19}$, and progressive mitral incompetence ${ }^{20}$.

In fact these together have been called 'The Mitral Prolapse Syndrome,21, implying that they are in themselves diagnostic of MVP; it is now apparent though that most of the papers suggesting clinical associations have been biased by the special selection of patients already affected by symptoms or complications ${ }^{22}$.

Several recent unbiased studies have shown that MVP, whether diagnosed by auscultation alone ${ }^{23}$, echocardiographically ${ }^{24}$, or by both methods ${ }^{25,26}$, is not associated with symptoms or with ECG changes. Cardiac arrhythmias are not more frequent than in the general population ${ }^{27}$. Sudden death, the most feared alleged complication, is extremely rare ${ }^{28,29}$ and may actually be less likely in those with MVP than others! $!^{29}$ cerebral embolus is also so rare in young people that it can be ruled out as a matter for concern ${ }^{30}$. Progressive mitral incompetence is unlikely even in those with murmurs ${ }^{28}$. The incidence of bacterial endocarditis in MVP is uncertain but it is not likely to occur in people who have only echocardiographic signs or in those who have only systolic clicks. Older male patients with mitral incompetent murmurs are probably at increased risk from endocarditis ${ }^{31}$ though prospective studies have not yet been carried out.

From the practical clinical point of view therefore $\vec{z}$ MVP seems to be a curiosity, of no greater relevance $\stackrel{\AA}{\unrhd}$ than an accessory nipple, except perhaps that men over $\bigcirc$ 45 years old with a definite mitral murmur need to be given advice about prophylaxis of infective endocarditis.

Unfortunately, 'labelling' someone as having MVP is $\overrightarrow{\vec{F}}$

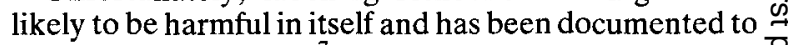
cause serious disability ${ }^{7}$. People who believe their heart is abnormal are more likely to adopt an invalid role and to complain of symptoms than if they were unaware of any abnormality. The diagnosis becomes the disease ${ }^{32}$.

\section{Historical Perspective}

The symptoms recently attributed to MVP are identical to those which affected a large number of $\vec{\omega}$ British soldiers during the First World War. Forty four thousand of these were medically discharged with an invalidity pension, most remaining chronically disabled, ? solely because Army doctors labelled them as having $\vec{\omega}$ heart disease when none was present ${ }^{33}$. The atypical of chest pain, undue breathlessness, palpitations, and other vague complaints were convincingly shown later $\dot{\circ}$

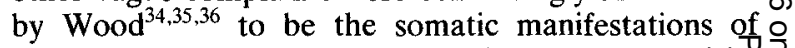
emotional arousal; they are, that is to say, caused by fear! This is of course greatly increased by the belief that $\vec{c}$ the heart is abnormal and the source of the symptom Obvious parallels can be drawn with MVP; the communication of this diagnosis and its suppose $\vec{\varphi}$ implications to the nervous people who tend to compla of palpitations, aches and pains, light-headedness increases the worry and of course tends to perpetuaes. the symptoms.

Wood convinced his RAMC colleagues in the Second World War that the concept of 'The Soldier's Heart' was in every way inappropriate as an explanation for emotional symptoms and the expensive fiasco of the earlier conflict was avoided. We also should avoid the errors of our First World War predecessors and should refrain from attributing symptoms to ill-defined heart disorders. Those who have been told already that they have MVP should be reassessed; it is not clinically relevant and may not even be present.

\section{Conclusion}

MVP remains a vague disorder. It does not cause symptoms and should not be diagnosed without unequivocal clinical evidence (which should be obvious $\delta$ to anyone with a stethoscope) and a great deal of careful consideration.

\section{REFERENCES}

1. WOOLEY C F. Where are the diseases of yesteryear? DaCosta's syndrome, soldier's heart, the effort syndrome, neurocirculatory asthenia - and the mitral valve prolapse syndrome. Circulation 1976; 53: 749-751. 
2. Read R C, Thal A P and Wendt V E. Symptomatic valvular myxomatous transformation (the floppy valve syndrome). A possible forme fruste of the Marfan syndrome. Circulation 1965; 32: 897-910.

3. Davies $\mathbf{M} \mathbf{J}$, Moore B $\mathbf{P}$ and Braimbridge $\mathbf{M}$.V. The floppy mitral valve. Study of incidence, pathology and complications in surgical, necropsy, and forensic material. Br Heart J 1978; 40: 468-481.

4. WALlER BF, et al. Etiology of clinically isolated, severe, chronic, pure mitral regurgitation: analysis of 97 patients over 30 years of age having mitral valve replacement. $\mathrm{Am}$ Heart J 1982; 104: 276-288.

5. BARLOW J B, et al. Late systolic murmur and non-ejection ("mid-late") systolic clicks. An analysis of 90 patients. $\mathrm{Br}$ Heart $J$ 1968; 30: 203-218.

6. Brigden W and Leatham A. Mitral incompetence. $\mathrm{Br}$ Heart J 1953; 15: 55-73.

7. Allen H, Harris A and Leatham A. Significance and prognosis of an isolated late systolic murmur: a 9 to 22 year follow-up. Br Heart $J$ 1974; 36: 525-532.

8. HuMphries J O'N and Mckusick V A. The differentiation of organic and "innocent" systolic murmurs. Prog Cardiovasc Dis 1962; 5:152-171.

9. LeVY D and SAVAGE D. Prevalence and clinical features of mitral valve prolapse. Am Heart J 1987; 113: 1281-1290.

10. Savage D D, et al. Mitral valve prolapse in the general population. 1. Epidemiological features: The Framingham Study. Am Heart J 1983; 106: 571-576.

11. MARKIEWICZ W, et al. Mitral valve prolapse in one hundred presumably healthy young females. Circulation 1976; 53: 464-473.

12. WANN L S, et al. Prevalence of mitral prolapse by two dimensional echocardiography in healthy young women. Br Heart J 1983; 49: 334-340.

13. DevereuX $\mathrm{R}$ B, et al. Diagnosis and classification of severity of mitral valve prolapse: methodologic, biologic, and prognostic considerations. Am Heart J 1987; 113: 1265 1280 .

14. LEVINE $\mathbf{R}$ A, et al. The relationship of mitral annular shape to the diagnosis of mitral valve prolapse. Circulation 1987; 75: 756-767.

15. Criley J M, et al. Prolapse of the mitral valve. Clinical and cine-angiocardiographic findings. Br Heart $J$ 1966; 28: 488496.

16. KENNETT J D, et al. Observer variation in the angiocardiographic diagnosis of mitral valve prolapse. Chest 1981; 79: 146-150.

17. HaNCOCK E W and COHN K. The syndrome associated with midsystolic click and late systolic murmur. Am J Med 1966; 41: 183-196.

18. Corrigall D, et al. Mitral valve prolapse and infective endocarditis. Am J Med 1977; 63: 215-222.

19. BARNETT $\mathbf{H ~ J ~ M , ~ e t ~ a l . ~ F u r t h e r ~ e v i d e n c e ~ r e l a t i n g ~ m i t r a l ~}$ valve prolapse to cerebral ischemic events. $N$ Eng $J$ Med 1980; 302: 139-144.

20. Mills P, et al. Long-term prognosis of mitral-valve prolapse. $N$ Eng J Med 1977; 297: 13-18.

21. VENKATESH A, et al. Mitral valve prolapse in anxiety neurosis. Am Heart $J$ 1980; 100: 302-305.

22. Motulsky A G. Biased ascertainment and the natural history of diseases. $N$ Eng J Med 1978; 298: 1196-1197.

23. URETSKY B F. Does mitral valve prolapse cause nonspecific symptoms? Int J Cardiol 1982; 1: 435-442.

24. Retchin S M, et al. Mitral valve prolapse. Disease or illness? Arch Intern Med 1986; 146: 1081-1084.

25. SAvaGE D D, et al. Mitral valve prolapse in the general population. 2. Clinical features: The Framingham Study. Am Heart J 1983; 106: 577-581.

26. DeVereux R B, et al. Relation between clinical features of the mitral prolapse syndrome and echocardiographically documented mitral valve prolapse. J Am Coll Cardiol 1986; 8: 763-772.

27. Savage D D, et al. Mitral valve prolapse in the general population. 3. Dysrhythmias: The Framingham Study. Am Heart $J$ 1983; 106: 582-586.

28. LeAthaM A and BRIGDEN W. Mild mitral regurgitationo and the mitral prolapse fiasco. Am Heart $J$ 1980; 99: 6590 664.

29. KLIGFIEld P, et al. Arrhythmias and sudden death in mitraf valve prolapse. Am Heart $J$ 1987; 113: 1298-1307.

30. Wolf P A and Sila C A. Cerebral ischemia with mitra $\bar{P}$ valve prolapse. Am Heart J 1987; 113: 1308-1315.

31. MaCMAHON $\mathrm{S}$ W, et al. Mitral valve prolapse and infective endocarditis. Am Heart J 1987; 113: 1291-1298.

32. Levine R A and WeYman A E. Mitral valve prolapse: disease in search of, or created by, its definition? Echocardiography 1984; 1: 3-14.

33. LEwIS T. The Soldier's Heart and The Effort Syndrome (2nd Edition). London: Shaw and Sons, 1940.

34. WOOD P. Da Costa's syndrome (or effort syndrome). $\mathrm{Br}$ Med J 1941; 1: 767-772.

35. Wood P. Da Costa's syndrome (or effort syndrome). The mechanism of the somatic manifestations. Br Med J 1941; 1: 805-811.

36. WoOD P. Aetiology of Da Costa's syndrome. $\mathrm{Br}$ Med J 1941; 1 : 845-850. 